\title{
The Effects of Mental Imagery and Cardiac Coherence on Mental Skills of Tunisian Karate Players at School Age
}

\author{
Sabeur Hamrouni ${ }^{*}$, Jaouad Alem², Sylvain Baert ${ }^{3}$, Ines Bouguerra ${ }^{4}$ \\ ${ }^{1}$ High Institute of Sport and Physical Education of Tunis, University of Manouba, Manouba, Tunisia \\ ${ }^{2}$ Physical Education School, Laurentian University, Greater Sudbury, Canada \\ ${ }^{3}$ University of Health and Law, Lille, France \\ ${ }^{4}$ High Institute of Sport and Physical Education of Sfax, University of Sfax, Sfax, Tunisia \\ Email: sabeurhamrouni@yahoo.fr
}

Received 27 February 2015; accepted 23 April 2015; published 27 April 2015

Copyright (C) 2015 by authors and Scientific Research Publishing Inc.

This work is licensed under the Creative Commons Attribution International License (CC BY). http://creativecommons.org/licenses/by/4.0/

c) (i) Open Access

\begin{abstract}
The aim of our research consisted in checking the influence of the mental coaching using the mental imagery and relaxation based on cardiac coherence, on the improvement of the cognitive, emotional and behavioural reactions of the Tunisian karate Elite at school age. Our study was about to check if the Tunisian karate Elite at school age who had undergone a mental coaching has a better mental profile than their counterparts of other sporting disciplines and karate players with usual training method. Our sample consisted on an experimental group ( $\mathrm{N}=24$ athletes) and control group ( $\mathrm{N}=22$ athletes), all aged from 16 to 19 years. The experimental group followed for 10 months a psychological and mental coaching. The control group continued to train normally for the same period of time. To assess the mental skills of the participants, we used the OMSAT-3 (Guelmami et al., 2014). Our study showed that a 10 month mental coaching was needed to improve 4 mental skills, i.e. "goal setting" "relaxation", "imagery" and "mental practices". Our findings sustained the importance of a three-dimensional mental coaching in relation to one basic skill (goal setting), a psychosomatic skill (relaxation) and two cognitive skills (imagery and mental practice).
\end{abstract}

\section{Keywords}

Mental Skills, Mental Coaching, Karate, School Age, OMSAT-3

\section{Introduction}

The improvement and consolidation of psychic abilities and mental skills of the athlete is one of the most im-

${ }^{*}$ Corresponding author.

How to cite this paper: Hamrouni, S., Alem, J., Baert, S., \& Bouguerra, I. (2015). The Effects of Mental Imagery and Cardiac Coherence on Mental Skills of Tunisian Karate Players at School Age. Advances in Physical Education, 5, 107-115.

http://dx.doi.org/10.4236/ape.2015.52014 
portant objectives of psychological and mental coaching in sport, particularly in high level sport. This kind of coaching is nowadays particularly provided as a motor imagery and relaxation program. Psychic abilities mean a set of psychological and emotional factors that influence the sporting activity and are at the same time influenced by it (Cox, 2005).

During the coaching of athletes, a particular interest must be granted to the interactions between the sportsman considered as a biological, psychological and cultural entity, in his space of motion.

The mental coaching is basically oriented towards the technical strategies and trainings techniques which make it possible for the sportspersons to progress and to better manage the environment of the game (Calmels \& Fournier, 1999). Much of the research in applied sport sciences agree that athletic successful performance is assured by a total package including physical, psychological, technical and tactical skills (Tenenbaum \& Eklund, 2007).

The mental coaching can be thus defined as a set of techniques which the athlete learns then applies in an autonomous way in order to develop his psychological abilities and to optimize his performance (Baert \& Dufour, 2007; Calmels et al., 2003) and it includes a set of techniques which the athlete needs to sharpen the sporting gesture and copy with the stress and their generating influences. Similarly, a regular practice of the physical activity supports a reduction of the depressive symptoms and the reinforcement of the psychological wellbeing (Guillot et al., 2010).

In fact, before seeking to make the athlete powerful, it is very necessary to take care of his personal fulfilment (Abrezol, 2002). To perform this goal several psychological strategies, procedures or methods can be set up or directly taught to the sportsmen in order to facilitate emotional rebalancing of the athlete and therefore enhance his psychological and mental resources. The modern concept for the physical and sporting activity is not only physical and motor but also psychological.

One of the most relevant objectives of the mental coaching and preparation strategies is to improve coping by the sportspersons to face frustrating situations, to regain self-confidence and progress towards autonomy and return to the physical and sporting activity. Indeed, the positive internal monologue, i.e. self-talk, or the supporting a locus of internal audit can have positive effects on the sporting performances (Orlick \& McCaffrey, 1991).

In the light of the above our research's approach can be considered as a monistic one to emphasise the holistic functioning of the body and the mind interactions' relationships.

A significant method of mental coaching is the motor imagery which enhances the mobility by increasing the range of motion and even reducing muscle pain (Hoyek et al., 2013). Another very actual technique is the cardiac coherence which is a synonym of coherent breathing that seems to be very helpful to enhance health, wellbeing and optimal performance by promoting optimal respiration, blood flow and by regulating the autonomic nervous system imbalance mainly in stress conditions (Schreiber, 2003).

As we know from physiological knowledge, our breath is a reflex activity and we can act upon it to modify and optimize our emotional balance. The physiological explanation lies in the heart rate acceleration by inhalation and in slowing down by exhalation. By the same time, the respiratory arterial pressure wave rises with exhalation and falls with inhalation (O’hare, 2012). Since the time period between each of our heartbeats is never exactly the same, i.e. heart rate variability, symmetric and harmonious heart variability, must be reached to provide an optimal stress monitoring skill in high sport competitions. In contrast, when heart rate variability is chaotic it would lead to anxious responses and activate the physiological system, which will be programmed to respond to stress. The many advantages of cardiac coherence have been demonstrated to regulate blood pressure, heart rate, brainwaves, muscle tension variation, skin conductivity, as well as overall bioenergetics potential of the sportsperson.

\section{Aims of the Research}

The aims of our research consisted in checking the influence of the mental coaching, while using the mental imagery and cardiac coherence sustained with relaxation techniques, on the cognitive aspects of young Tunisian karate students belonging to the Tunisian karate elite and on the improvement of their emotional and behavioural reactions. We also aimed to know if the mental coaching of these athletes helps them to a better mental and emotional recovering.

In other words, we aimed to test if motor imagery and cardiac coherence can help improving certain mental skills as goal setting, competition planning, relaxation ability and mental practice.

The Tunisian karate players at school age who have undergone a mental support sessions in the form of mental trainings program have got better mental profile by getting profit of certain mental skills like goal setting, 
competition planning, ability to relaxation, imagery and mental practice, as their counterparts from other sporting disciplines or karate experts who did not get benefit of this form of training, and continued to train normally.

In other words, a 10 months methodical and systematic mental coaching program in the form of cardiac coherence, relaxation, breathing exploration and motor imagery (independent variable) can consolidate and enhance some mental skills (dependent variable) at top level Tunisian karate players at school age.

\section{Method}

\subsection{The Assessment of the Mental Skills}

To assess the mental skills of the athletes we used the OMSAT-3 "The third version of the Ottawa Mental Skills Assessment Tool”, Durand-Bush \& Salmela (2001) validated in the study of Guelmami (Guelmami et al., 2014). The assessment occurred in two times: one time at the first and one at the last session for the 2 groups).

12 subscales of the OMSAT-3 are measured with a Likert scale at 7 points $(1=$ strongly disagree, $7=$ strongly agree).

The initial version of the OMSAT-3 ranged the subscales in 3 categories these are:

1) Basic Skills (goal setting, self-confidence, and commitment);

2) Psychosomatic Skills (stress reaction, fear control, relaxation, activation); and

3) Cognitive Skills (imagery, mental practice, focusing,refocusing, competition planning).

\subsection{The Sample of the Study}

A set of $\mathrm{N}=46$ sportspeople randomly recruited among Tunisian karate players at school age and belonging to the Tunisian karate elite took part to the research. The age of the participants was ranging from 16 to 19 years and the mean age $=17.1$. All participants were divided into 2 groups: an experimental group made up of 24 athletes (17 male and 4 female) and a control group composed of 22 athletes (13 male and 9 female).

Prior to the commencement of the study we asked for permission from the Tunisian Federation of Karate for the purpose of our research. All players were informed about the procedures of the study before providing their verbal consent to participate and were asked to complete the OMSAT-3 questionnaire in 40 min after training. At the beginning of the questionnaire, an introductory page appears, informing participants about the anonymity of their answers and instructing them to answer as correctly and honestly as possible. No inducement was offered for participation in the study.

The experimental group has undergone for 10 months (from May 2013 to February 2014) two sessions a week during 60 minutes approximately, of psychological and mental coaching. The coaching sessions were programmed after sport training sessions. The control group continued to train normally in the form of usual technical-tactical sport training.

The contents of the sessions of the experimental group are summarised in Table 1.

\subsection{Statistical Analysis}

The statistical data management and computations of statistics were performed using SPSS version 20.0 (SPSS Inc., Chicago, IL, USA).

Prior to the analysis of the effect of the independent variable on the dependent variable we estimated the internal consistency degree of the items (Cronbach, 1951) and then we proceeded to the measures of the effect of the 10-month program of mental coaching (VI) with the Student test for two independent samples (Brown \& Forsythe, 1974; Conover, Johnson, \& Johnson, 1981; Olejnik \& Algina, 1987).

\section{Results}

- Estimation of the internal consistency

Table 2 shows that only 6 of 12 mental skills of the OMSAT-3 have been identified to achieve the statistical analysis: (Alpha $\min \geq 0.62$ ).

These mental skills are: goal setting, relaxation, imagery, mental practice, focusing and competition planning.

- The effect of IV (mental coaching program) on DV (mental skills) 
Table 1. Contents of mental coaching.

\begin{tabular}{|c|c|c|}
\hline Months & Content & Expected goal \\
\hline $1^{\text {st }}$ and $2^{\text {nd }}$ Month & $\begin{array}{l}\text { Cardiac coherence } \\
\text { Instructions: } 5 \text { seconds inhale and } 5 \text { seconds exhale preceded } \\
\text { with: } \\
\text { - } \quad \text { Relaxations training (differential and progressive relaxation), } \\
\text { - } \quad \text { Respiratory explorations based on the abdominal technique }\end{array}$ & $\begin{array}{ll}\text { - } & \text { Relaxation } \\
\text { - } & \text { Activation } \\
\text { - } & \text { Emotional balance } \\
\text { - } & \text { Searching symmetric variability }\end{array}$ \\
\hline $3^{\text {rd }}$ and $4^{\text {th }}$ Month & $\begin{array}{l}\text { Motor Imagery related to the technique with simple exercises } \\
\text { (regulation of emissivity) in mental evocation of the force and } \\
\text { speed parameters }\end{array}$ & $\begin{array}{ll}\text { - } & \text { Motor imagery regulation } \\
\text { - } & \text { Enhancement of motor program } \\
\text { - } & \text { Focusing }\end{array}$ \\
\hline $\begin{array}{c}5^{\text {th }} \text { and } 6^{\text {th }} \\
\text { Month }\end{array}$ & $\begin{array}{l}\text { - The future imagery while visualizing next coming combats } \\
\text { without anxiety } \\
\text { - Takeover of the cardiac coherence technique to slow down } \\
\text { anxiety in imaged stressful situations }\end{array}$ & $\begin{array}{ll}\text { - } & \text { Coping } \\
\text { - } & \text { Relaxation } \\
\text { - } & \text { Activation } \\
\text { - } & \text { Emotional balance }\end{array}$ \\
\hline $7^{\text {th }}$ Month & The last imagery (positive sporting memories) & $\begin{array}{ll}\text { - } & \text { Self-confidence } \\
\text { - } & \text { Fear control }\end{array}$ \\
\hline $8^{\text {th }}$ Month & $\begin{array}{l}\text { Developing of strategies with internal prospect (awakening of the } \\
\text { kinaesthetic feelings) and external awakening for the visual and } \\
\text { auditory feelings) }\end{array}$ & $\begin{array}{l}\text { - } \quad \text { Sharpening of the motor execution } \\
\text { - } \quad \text { Enhancement of mental imagery and } \\
\text { mental practice } \\
\text { - } \quad \text { Focusing }\end{array}$ \\
\hline $9^{\text {th }}$ Month & $\begin{array}{l}\text { Mental chronometry (time measured and rehearsed imagery of } \\
\text { movement sequences) }\end{array}$ & $\begin{array}{l}\text { - } \quad \text { Sharpening of the motor execution } \\
\text { - } \quad \text { Enhancement of mental imagery and } \\
\text { mental practice } \\
\text { - } \quad \text { Focusing }\end{array}$ \\
\hline $10^{\text {th }}$ Month & $\begin{array}{l}\text { - The self-talk (or internal monologue) and actual thoughts of } \\
\text { the moment goal setting oriented i.e. targeted attack or } \\
\text { watching position } \\
\text { - Takeover of the cardiac coherence technique }\end{array}$ & $\begin{array}{ll}\text { - } & \text { Self-confidence } \\
\text { - } & \text { Awareness of goal setting } \\
\text { - } & \text { Relaxation } \\
\text { - } & \text { Activation } \\
\text { - } & \text { Emotional balance } \\
& \text { Optimization of mindfulness while }\end{array}$ \\
\hline
\end{tabular}

Table 2. The internal consistency analyses for the 12 subscales.

\begin{tabular}{|c|c|c|}
\hline Subscale & Pretest Alpha and deleted items & Postest Alpha and deleted items \\
\hline Goal setting & 0.76 I set hard but achievable goals & 0.76 \\
\hline Self-confidence & $\begin{array}{l}\text { This dimension is not considered in the calculations, it is eliminated } \\
\text { (alpha }=-1.12 \text {, impossible to optimize alpha to make it acceptable }\end{array}$ & Subscale eliminated \\
\hline Commitment & Eliminated dimension & Subscale eliminated \\
\hline Stress reaction & Eliminated dimension & Subscale eliminated \\
\hline Control of fear & Eliminated dimension & Subscale eliminated \\
\hline Relaxation & 0.81 I relax quickly and easily & 0.81 \\
\hline Activation & Eliminated dimension & Subscale eliminated \\
\hline Imagery & $\begin{array}{l}0.842 \text { items deleted: My mental evocations are clear. } \\
\text { I can easily change the evocation in my head }\end{array}$ & 0.84 \\
\hline Mental practice & 0.68 My mental practice is planned & 0.68 \\
\hline Focusing & 0.62 & 0.62 \\
\hline Refocusing & Eliminated dimension & Subscale eliminated \\
\hline Competition planning & $\begin{array}{l}0.67 ; 2 \text { items deleted: I am planning a series of things to do before a } \\
\text { competition, I am planning a series of things to think about during a } \\
\text { competition }\end{array}$ & 0.67 \\
\hline
\end{tabular}


Checking the group equivalence:

After estimating the values of the group equivalence in pretest condition by the use of Levene's test for equality of variances as it's shown in Table 3, we propose to check the t-test for equality of means for the different subscales in the pretest (Levene, 1960).

In Table 4 the values of T-test for equality of means indicate that the 2 groups (experimental and control group) are equal for the 5 subscales except for focusing where the experimental group got a higher mean $(\mathrm{t}=$ $4.03^{* * *}$ ).

We should then compare the values of the 2 groups in the posttests but not for the subscale "focusing". For this subscale we compared the benefit for the 2 groups and we have been very aware of the conservative aspect of this technique.

After estimating the values of the group equivalence in post test condition by the use of Levene's test for equality of variances as it's shown in Table 5 we propose to check the t-test for equality of means for the different subscales in the posttest.

We have retained the subscales that have proven a significant difference between the experimental and the control group after using Levene's test for equality of variances. These subscales are presented in Table 6 .

For the sub-skill "competition planning" there is no significant difference between experimental and control group: $\mathrm{t}=1.57, p=12.4 \%$, and paradoxically for the sub-skill "focusing", the experimental group regresses, while the control group increased $(\mathrm{t}=-11.16)$.

As it's shown in Table 7 the significant retained subscales for the experimental group are "Goal setting" as a basic skill, "Relaxation” as psychosomatic skill, "Imagery and Mental practice” as cognitive skills.

Table 3. Checking the group equivalence in pretest condition with a t-test for 2 independent samples.

\begin{tabular}{|c|c|c|c|c|}
\hline Subscale & Group & $\mathrm{N}$ & Mean & Std Deviation \\
\hline \multirow{2}{*}{ Goal setting } & Experimental & 24 & 3.6667 & 1.21186 \\
\hline & Control & 22 & 3.7424 & 1.22984 \\
\hline \multirow{2}{*}{ Relaxation } & Experimental & 24 & 3.3750 & 1.14340 \\
\hline & Control & 22 & 3.4394 & 1.36233 \\
\hline \multirow{2}{*}{ Imagery } & Experimental & 24 & 3.4167 & 1.17646 \\
\hline & Control & 22 & 3.5455 & 1.33550 \\
\hline \multirow{2}{*}{ Mental practice } & Experimental & 24 & 3.3056 & 0.95258 \\
\hline & Control & 22 & 2.7727 & 1.08568 \\
\hline \multirow{2}{*}{ Focusing } & Experimental & 24 & 5.5312 & 0.79848 \\
\hline & Control & 22 & 4.5000 & 0.93541 \\
\hline \multirow{2}{*}{$\begin{array}{l}\text { Competition } \\
\text { planning }\end{array}$} & Experimental & 24 & 4.3333 & 1.11965 \\
\hline & Control & 22 & 3.7727 & 1.30683 \\
\hline
\end{tabular}

Table 4. T-test for equality of means.

\begin{tabular}{cccc}
\hline Subscale & \multicolumn{3}{c}{ Sig. (2-tailed) } \\
\cline { 2 - 4 } Goal setting & $\mathrm{t}$ & $\mathrm{t}$-test for Equality of Means & 0.834 \\
& -0.210 & 44 & 0.835 \\
Relaxation & -0.210 & 43.532 & 0.863 \\
& -0.174 & 44 & 0.864 \\
Imagery & -0.173 & 41.194 & 0.730 \\
Mental practice & -0.348 & 44 & 0.731 \\
& -0.346 & 42.067 & 0.083 \\
Focusing & 1.773 & 44 & 0.085 \\
& 1.763 & 42.000 & 0.000 \\
Competition planning & 4.032 & 44 & 0.000 \\
\hline
\end{tabular}


Table 5. Checking the group differences in the post test with the t test for 2 independent samples.

\begin{tabular}{|c|c|c|c|c|}
\hline Subscale & Group & $\mathrm{N}$ & Mean & Std Deviation \\
\hline Goal setting & $\begin{array}{l}\text { Experimental } \\
\text { Control }\end{array}$ & $\begin{array}{l}24 \\
22\end{array}$ & $\begin{array}{l}5.4306 \\
4.0606\end{array}$ & $\begin{array}{l}0.76442 \\
1.15303\end{array}$ \\
\hline Relaxation & $\begin{array}{l}\text { Experimental } \\
\text { Control }\end{array}$ & $\begin{array}{l}24 \\
22\end{array}$ & $\begin{array}{l}5.5000 \\
3.5455\end{array}$ & $\begin{array}{l}0.79855 \\
1.31151\end{array}$ \\
\hline Imagery & $\begin{array}{l}\text { Experimental } \\
\text { Control }\end{array}$ & $\begin{array}{l}24 \\
22\end{array}$ & $\begin{array}{l}5.9792 \\
3.5455\end{array}$ & $\begin{array}{l}0.82724 \\
1.22386\end{array}$ \\
\hline Mental practice & $\begin{array}{l}\text { Experimental } \\
\text { Control }\end{array}$ & $\begin{array}{l}24 \\
22\end{array}$ & $\begin{array}{l}5.4306 \\
2.8182\end{array}$ & $\begin{array}{l}1.00952 \\
1.07264\end{array}$ \\
\hline Competition planning & $\begin{array}{l}\text { Experimental } \\
\text { Control }\end{array}$ & $\begin{array}{l}24 \\
22\end{array}$ & $\begin{array}{l}4.3333 \\
3.7727\end{array}$ & $\begin{array}{l}1.11965 \\
1.30683\end{array}$ \\
\hline Focusing & $\begin{array}{l}\text { Experimental } \\
\text { Control }\end{array}$ & $\begin{array}{l}24 \\
22\end{array}$ & $\begin{array}{c}-2.2812 \\
0.2273\end{array}$ & $\begin{array}{l}1.02234 \\
0.39271\end{array}$ \\
\hline
\end{tabular}

Table 6. T-test for equality of means.

\begin{tabular}{|c|c|c|c|}
\hline \multirow{2}{*}{ Subscale } & \multicolumn{3}{|c|}{ t-test for Equality of Means } \\
\hline & $\mathrm{t}$ & df & Sig. (2-tailed) \\
\hline Goal setting & $\begin{array}{l}4.787 \\
4.705\end{array}$ & $\begin{array}{c}44 \\
35.996\end{array}$ & $\begin{array}{l}0.000 \\
0.000\end{array}$ \\
\hline Relaxation & $\begin{array}{l}6.164 \\
6.039\end{array}$ & $\begin{array}{c}44 \\
34.102\end{array}$ & $\begin{array}{l}0.000 \\
0.000\end{array}$ \\
\hline Imagery & $\begin{array}{l}7.961 \\
7.830\end{array}$ & $\begin{array}{c}44 \\
36.438\end{array}$ & $\begin{array}{l}0.000 \\
0.000\end{array}$ \\
\hline Mental practice & $\begin{array}{l}8.509 \\
8.486\end{array}$ & $\begin{array}{c}44 \\
43.039\end{array}$ & $\begin{array}{l}0.000 \\
0.000\end{array}$ \\
\hline Competition planning & $\begin{array}{l}1.566 \\
1.556\end{array}$ & $\begin{array}{c}44 \\
41.580\end{array}$ & $\begin{array}{l}0.124 \\
0.127\end{array}$ \\
\hline Focusing & $\begin{array}{l}-10.794 \\
-11.156\end{array}$ & $\begin{array}{c}44 \\
30.145\end{array}$ & $\begin{array}{l}0.000 \\
0.000\end{array}$ \\
\hline
\end{tabular}

Table 7. The retained significant 4 subscales for the experimental versus control group.

\begin{tabular}{cc} 
Sub-scale & $\mathrm{t}$-test \\
\hline 1. Goal setting & $\mathrm{t}=4.71^{* * *}$ \\
2. Relaxation & $\mathrm{t}=6.04^{* * *}$ \\
3. Imagery & $\mathrm{t}=7.83^{* * *}$ \\
4. Mental practice & $\mathrm{t}=8.51^{* * *}$ \\
\hline
\end{tabular}

${ }_{\text {s** }}^{*}$ ignificant with $\mathrm{p}<0.001$.

\section{Discussion}

Our mental coaching program which has included cardiac coherence and motor imagery improves 4 of 6 mental skills; these skills are: 1$)$ Goal setting $\left.(t=4.71)^{* * *}, 2\right)$ Relaxation $\left(t=6.04^{* * *}\right)$, 3) Imagery $\left(t=7.83^{* * *}\right)$ and 4) Mental practice $\left(t=8.51^{* * * *}\right)$. The post-test results have shown that our mental coaching program contributes to the improvement of 4 mental skills out of 6 .

Indeed, the experimental group has got better profit then the control group, from the experimental treatment, in the form of mental coaching, on some mental skills.

These skills seem to be very important mental resources that support excellence in sport performance by the Tunisian karate players at school age.

Our findings seem to be in harmony with some empirical researches of the two last decades that have identified some of the most relevant mental skills which characterize the elite athletes in a lot of sports disciplines. 
Those skills are basically relaxation (Durand-Bush \& Salmela, 2002; Gould et al., 1993) and mental imagery i.e. motor imagery (Calmels et al., 2003). Likewise, recent studies, for example, those of Andrew et al. (2007) and Demuth et al. (2007) have shown that mental skills like motivation, stress reaction, fear control, self-confidence, relaxation and mental effectiveness are the most characterizing mental traits of the elite athletes. These findings are not fully concordant with those of Williams and Krane (2001) that have identified some other mental skills specifying Olympic success like high confidence, self-talk, commitment and control strategies.

Finally, in the light of all these findings we can consider that the enhancement of the sub-skill "goal setting" marks a significant and distinguishing future of our study.

On the other hand the sub-skill "relaxation" has been also proven as one of the most important mental skills by the young Tunisian karate players in our study. Indeed when athletes are under pressure they generally don't perform well and they may be focusing too much on their own movements rather than relying on their motor skills that have been developed through several years of practice.

From all these findings the sub-skill "relaxation" seems to be very important and must be therefore integrated in the mental coaching program to improve more motor efficiency by top level athletes mainly in stress situations, i.e. pre-competitive training. The plausible explanation for this integration proposal would be lying in the technique of cardiac coherence that allows the karate players to progress in their inner self-management.

From another perspective the mental imagery and the mental practice, often referred as motor imagery, are primarily related to the technique of the movement execution, which is likely to support better movement availability and a better profit of performance while acting positively on the improvement and the sharpening of certain parameters of the movement. This beneficial effect was supported and shown in works by Louis et al. (2008) who showed that the real execution of a kata was carried out more quickly following a drive in accelerated imagery. It has been proven that, in the field of the movement execution, the advantages of the mental imagery also makes it possible to facilitate action mobility by increasing the amplitude of the movement and reducing muscular pains (Hoyek et al., 2013). It should be noted that slowing down the motor imagery at the beginning of the learning process of motor tasks can help the individual to increase control ability of the mental image and makes it clearer. Progressively the sportsperson will have to visualize the motor task at real speed (Thill, 1998).

Other research also has shown that the imagery related with relaxation was more efficient than imagery alone (Calmels \& Fournier, 1999) which is very consistent with the results of our study. The beneficial effects of our program of mental coaching based on motor imagery and relaxation has been thus corroborated.

Indeed most of our athletes were more able to manage the end of combat where the issue was also highly competitive. The use of relaxation strategies, abdominal breathing and focusing on the release of defensiveness to reduce a high level of anxiety, has been also shown.

On the other hand studies conducted by "Filimon" using the technique of mindfulness have shown its effectiveness on performance in table tennis, with visible improvements in self-confidence, control of fear, ability to control distractions and refocusing (Filimon et al., 2012).

Thus, mindfulness has been proved to have a positive effect on these variables, by contrast with our study which demonstrated the beneficial effects of the mental coaching based primarily on the imagery of the technique (or movement imagery) and the imagery of relaxation on mental skills like "goal setting", "relaxation", "imagery" and "mental practice".

The complementarities between these two studies will make it possible to expand the effects of the mental coaching to a greater number of mental skills. A possible explanation of this proposal may lie in the nature of the technique of mindfulness as a technique that consists in focusing on mental consistency. Mindfulness training is a powerful tool that enables sportsmen to maintain concentration (flow states) and defuse the interference from being distracted. When you are in flow, your brain experiences an energy transfer, shutting down the prefrontal cortex (cognitive control) allowing you to access your unconscious. It allows your body to do what it's capable of doing, without mental resistance or a high focusing.

Finally it can be stated that the 4 mental skills that have been improved by our mental coaching program can be considered as very significant for the Tunisian karate players at school age.

Although, our study revealed no significant difference between experimental and control group for the sub-skill "competition planning": $(\mathrm{t}=1.57, p=12.4 \%)$. Paradoxically for the sub-skill "focusing" the experimental group regresses, while the control group increased $(t=-11.16$.).

Some explanatory assumptions could partly explain these unexpected results: 
- The first assumption is that the karate players were post-tested right before a major competition; this could have caused the "disruption" of their competence to plan a competition. On the other hand our coaching program didn't involve clear competition strategies or tactical combat's traits to be recalled later!

- The second one: we compared the profits in competence in "mental focusing" of the two groups, this technique of analysis may have "penalized" the group of the karate players insofar as its average at the pre-test was higher at the beginning (plate effect).

- The third one: we estimated that experimental group had learned all a long our coaching sessions a better dealing with focusing strategy with relaxation techniques. Then as we know, athletes usually perform better when they trust their bodies rather than thinking too much about their own actions or what their coaches told them during practice (Beckmann et al., 2008). On the other hand, for skilled athletes, many movements such as kicking a soccer ball or completing a judo kick become automatic with little conscious thought.

- As we know, athletes usually perform better when they trust their bodies rather than thinking too much about their own actions or what their coaches told them during practice. In fact, consciously trying to keep one's balance is likely to produce imbalance and many movements of the body can be impaired by attempts at consciously controlling them.

\section{Prospects}

Our findings highlighted the following recommendations:

1) For all the athletes we recommend the cardiac coherence technique to maintain the balance between respiratory, cardiac and cerebral functioning leading to a holistic mobilisation of the organism in sport mainly in stress situations

2) We recommend the use of the cardiac coherence technique to optimise motor imagery and a better involvement in the mental practice

3) For the expert athletes the mental imagery technique must be performed in accelerated way in sessions of mental practice in order to improve the speed of the movement execution

4) The motor imagery technique must be chosen at slow motion in order to improve the quality of the motor learning especially by novice.

Moreover, we also highlight the need to implement other techniques based primarily on the full conscience, i.e. mindfulness, in sport to improve self-confidence, fear control, control of distractions and refocusing. These techniques seem to be very consistent with cardiac and respiratory coherence and therefore very useful for a mental coaching program.

At the end the 4 skills enhanced by our program may also mirror the flow area or "the optimum operating zone” also called: “Optimal experience” (Csikszentmihalyi, 2006). It’s about a feeling which creates an orderharmony-in our state of consciousness and strengthens the self. This optimal experience or Autotelic-Experience can be located between two critic mental traits: "excitation" and "excess of control". It's a very significant state that would emerge from our training program built basically on cardiac coherence, relaxation training, and imagery in the form of evocation of significant emotions and combat-sensations.

\section{Conclusion}

Our study showed that a 10-month mental coaching based on motor imagery exercises and cardiac coherence with muscular relaxation, respiratory exploration, is needed to improve 4 mental skills. These 4 skills are: goal setting, relaxation, mental imagery and mental practice.

These results are supposed to be very operational and would argue in favor of the importance of a three-dimensional mental coaching targeted with at least a basic skill (goal setting), a psychosomatic skill (relaxation and coping) and 2 cognitive skills (imagery and mental practice).

For the subs-skill "competition planning", there was no difference between the 2 groups and for another dimension "focusing", it was the control group who had got the most profit.

\section{Acknowledgements}

The authors would like to thank all the karate players for their involvement and precious cooperation. The authors also wish to thank all karate trainers and the Tunisian federation of karate. 


\section{References}

Abrezol, R. (2002). Searching Excellence, How to Improve Performance? Vivez Soleil.

Andrew, M., Grobbelaar, H., \& Wand Potgieter, J. C. (2007). Sport Psychological Skill Levels and Related Psychosocial Factors That Distinguish between Rugby Union Players of Different Participation Levels. Physical Education and Recreation, 29, 1-14. http://dx.doi.org/10.4314/sajrs.v29i1.25951

Baert, S., \& Dufour, Y. (2007). Coping and Emotion in Physical Education and Sport: Interests and Contributions to Mental Preparation. Physical Education and Sports Contribution to Education and Wellbeing (pp. 103-128). Regional AEEPS of Lille.

Beckmann, J., \& Elbe, A. (2008). Practice of Sport Psychology in Combat and Sport Performance and Combat Sports. Balingen: Spitta.

Brown, M. B., \& Forsythe, A. B. (1974). The Small Sample Behavior of Some Statistics with Test of Equality of Several Means. Tecnometrics, 16, 129-132. http://dx.doi.org/10.1080/00401706.1974.10489158

Calmels, C., \& Fournier, J. (1999). The Effects of a Mental Training Program Combined with a Physical Practice of Gymnastic on the Enhancement of Imagery. STAPS Journal France, 49, 64-68.

Calmels, C., Arripe-Longueville, F., Fournier, J. F., \& Soulard, A. (2003). Mental Skills among Elite Female Gymnasts: An Exploration of the Relative Influence of Mental Training and Natural Learning Experiences. International Journal of Sport Exercise Psychology, 1, 327-352. http://dx.doi.org/10.1080/1612197X.2003.9671724

Conover, W. J., Johnson, M. E., \& Johnson, M. M. (1981). A Comparative Study of Test for Homogeneity of Variance with Applications to the Outer Continental Shelf Bidding Data. Tecnometrics, 23, 357-361. http://dx.doi.org/10.2307/1268225

Cox, R. H. (2005). Psychologie du Sport (pp. 331-344). Bruxelles: De Boeck.

Cronbach, L. J. (1951). Coefficient Alpha and the Internal Structure of Tests. Psychometrika, 16, 297-334. http://dx.doi.org/10.1007/BF02310555

Csikszentmihalyi, M. (2006). A Life Worth Living: Contributions to Positive Psychology. New York: Oxford University Press.

Demuth, A., Czerniak, U., Krzykata, M., Wielinski, D., \& Ziotkowska-lajp, E. (2007). Somatic Characteristic of Players Form Chosen National Teams of Field Hockey. Human Movement, 8, 21-31.

Durand-Bush, N., \& Salmela, J. H. (2001). The Development of Talent in Sport. New York: Wiley.

Durand-Bush, N., \& Salmela, J. H. (2002). The Development and Maintenance of Expert Athletic Performance: Perceptions of World and Olympic Champions. Journal of Applied Sport Psychology, 14, 154-171. http://dx.doi.org/10.1080/10413200290103473

Filimon, L., \& Fournier, J. (2012). The Effect of Mindfulness Intervention on Table Tennis Performance: Case Study. Presented at the National Study Days of the French Society of Sport Psychology.

Gould, D., Jackson, S., \& Finch, L. (1993). Applied Research Life at the Top: The Experiences of U.S. National Champion Figure Skaters. Sport Psychologist, 7, 354-374.

Guelmami, N., Hamrouni, S., \& Agrebi, B. (2014). Psychological Profiles of Talented Male Youth Athletes in Team Sports Games. Journal of Physical Education and Sport Management, 5, 5-10.

Guillot, A., Tolleran, C., \& Collet, C. (2010). Does Motor Imagery Enhance Stretching and Flexibility? Journal of Sports Sciences, 28, 291-298. http://dx.doi.org/10.1080/02640410903473828

Hoyek, N., Di Rienzo, F., Collet, Ch., Hoyek, F., \& Guillot, A. (2013). The Therapeutic Role of Motor Imagery on the Functional Rehabilitation of a Stage II Shoulder Impingement Syndrome. Disability and Rehabilitation, 36, 1113-1119.

Levene, H. (1960). Contributions to Probability and Statistics (pp. 278-292). Redwood City, CA: Stanford University Press.

Louis, M., Guillot, A., Maton, S., Doyon J., \& Collet C. (2008). Effect of Imagined Movement Speed on Subsequent Motor Performance. Journal of Motor Behavior, 40, 117-132. http://dx.doi.org/10.3200/JMBR.40.2.117-132

O’hare, D. (2012). Cardiac Coherence 365. Paris: Thierry Souccar.

Olejnik, S. J., \& Algina, J. (1987). Type I Error Rates and Power Estimates of Selected Parametric Tests of Scale. Journal of Educational Statistics, 12, 45-61. http://dx.doi.org/10.2307/1164627

Orlick, T., \& McCaffrey, N. (1991). Mental Training with Children for Sport and Life. The Sport Psychologist, 5, $322-334$.

Schreiber, D. S. (2003). Healing Stress, Depression Anxiety without Medicals Neither Psychanalyse. Paris: Robert Laffont.

Tenenbaum, G., \& Eklund, R. (2007). Handbook of Sport Psychology ( $3^{\text {rd }}$ ed.). Hoboken, NJ: Wiley \& Sons.

Thill, E., \& Fleurance, P. (1998). Practical Guide of Psychological of the Sportsman. Paris: Vigot.

Williams, J. M., \& Krane, V. (2001). Psychological Characteristics of Peak Performance. In J. M. Williams (Ed.), Applied Sport Psychology: Personal Growth to Peak Performance (4th ed., pp. 137-147). Mountain View, CA: Mayfield. 